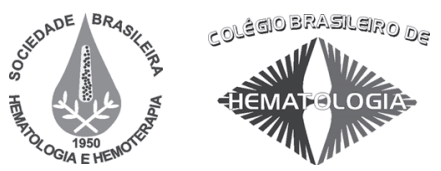

\title{
Potencial terapêutico das células-tronco de medula óssea no tratamento da epilepsia
}

\author{
Therapeutic potential of bone marrow stem cells in epilepsy treatment
}

Maria Julia M. Carrion ${ }^{1}$

Gianina T. Venturin ${ }^{2}$

Jaderson C. DaCosta ${ }^{3}$

\begin{abstract}
Epilepsia é uma patologia bastante prevalente no nosso meio. Há um número significativo de pacientes que não obtém resposta com a terapêtica medicamentosa, o que motivou a pesquisa de novas terapêuticas. O conceito de neurogênese no cérebro adulto, hoje já amplamente conhecida, principalmente a que ocorre na zona subventricular e na zona subgranular do giro denteado, motivou o desenvolvimeto de técnicas que aproveitassem esse mecanismo na tentativa de obtenção de efeitos antiepileptogênicos e reparadores. A maior parte dos estudos em vigência hoje, e que buscam tal finalidade, trabalha o uso de transplante de células progenitoras neurais ou de células fetais em modelos experimentais. No entanto, a terapêutica com células-tronco de medula óssea parece bastante interessante e promissora. Em doenças neurológicas nas quais os danos são frequentemente irreversíveis, as estratégias regenerativas podem representar um novo caminho. Em nosso laboratório, temos estudado o potencial terapêutico de células-tronco da medula óssea no controle de crises espontâneas recorrentes associadas ao modelo da pilocarpina com resultados excelentes. Também já está em andamento o primeiro estudo em humanos utilizando células-tronco de medula óssea para o tratatamento da epilepsia. Rev. Bras. Hematol. Hemoter. 2009;31(Supl. 1):112-119.
\end{abstract}

Palavras-chave: Células-tronco; medula óssea; epilepsia.

\section{Introdução}

Epilepsia é um distúrbio cerebral caracterizado por predisposição a geração de crises epilépticas e pelas consequências neurobiológicas, cognitivas, fisiológicas e sociais dessa condição. ${ }^{1}$ As manifestações clínicas da epilepsia (crises) são recorrentes e espontâneas, isto é, recorrem mesmo na ausência de doença tóxica metabólica ou estado febril. ${ }^{2,3}$ Estas manifestações clínicas são causadas pelo disparo intenso, sincronizado e ritmico de populações neuronais no sistema nervoso central. ${ }^{4}$
A incidência de epilepsia tem sido estimada em até 100 casos por 100 mil pessoas em países em desenvolvimento. ${ }^{5,6}$ A prevalência no nosso meio é estimada em 16,5 - 20,3/1000 respectivamente para a epilepsia ativa e inativa em Porto Alegre (Fernandes, JG. "Epidemiologia das crises epilépticas em Porto Alegre: um estudo populacional." Tese de Doutorado, Curso de Pós-Graduação em Medicina, Universidade Federal do Rio Grande do Sul, Porto Alegre, 1993). Cerca de 10\%$20 \%$ dos pacientes têm suas crises inadequadamente tratadas e 30\% apresentam resistência à terapia medicamentosa. Entre as epilepsias refratárias ao tratamento clínico, aque-

${ }^{1}$ Médica Neurologista do Hospital São Lucas da PUCRS e pesquisadora do Instituto do Cérebro (InsCer) - Porto Alegre-RS.

${ }^{2}$ Farmacêutica e pesquisadora do Instituto do Cérebro (InsCer) - Porto Alegre-RS.

${ }^{3}$ Professor Titular de Neurologia, Faculdade de Medicina da Pontifícia Universidade Católica do Rio Grande do Sul. Diretor do Instituto

do Cérebro (InsCer) e Coordenador do Laboratório de Sinalização Celular do Instituto de Pesquisas Biomédicas (IPB) da PUCRS.

Serviço de Neurologia do Hospital São Lucas da PUCRS - Programa de Pós-Graduação em Neurociências da PUCRS - Instituto do Cérebro (InsCer) da PUCRS - Instituto de Pesquisas Biomédicas (IPB) da PUCRS.

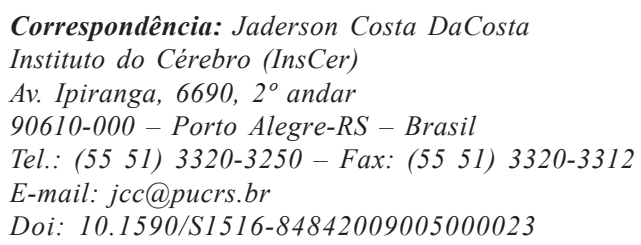


las com crises parciais complexas com origem no lobo temporal são as mais frequentes.

\section{Epilepsia do lobo temporal e a refratariedade terapêutica}

A epilepsia do lobo temporal (ELT) é reconhecida como uma síndrome altamente prevalente, que atinge $40 \%$ dos indivíduos que apresentam convulsões. Usualmente, a ELT é refratária às drogas antiepilépticas e é cirurgicamente tratável.

A maior parte dos pacientes com ELT apresenta à ressonância magnética do encéfalo sinais indicativos de esclerose mesial temporal (EMT). ${ }^{7}$ A EMT é definida por suas particularidades anatômicas, caracteristicamente esclerose hipocampal (EH) associada a graus variáveis de gliose e perda neuronal no hipocampo, subiculum, giro para-hipocampal e córtex temporal inferomedial. A EH consiste na perda neuronal e gliose marcadas no campo CA1 de Sommer e hilo hipocampal, menos visível em CA3 e CA4 , com preservação relativa da estrutura de CA2 ${ }^{8,9}$

As alterações patológicas no hipocampo e região parahipocampal, implicadas na epileptogênese ${ }^{8,9}$ estão relacionadas à reorganização estrutural e celular da formação hipocampal, neurodegeneração seletiva, mudanças na expressão e função de receptores de neurotransmissores e canais iônicos. ${ }^{10}$ Os danos neuronais evidenciados no hipocampo parecem ser decorrentes de uma liberação excessiva de glutamato no decorrer dos episódios comiciais, que produz nos neurônios pós-sinápticos um excessivo influxo de cálcio. ${ }^{11}$

Clinicamente, a EMT manifesta-se por crises parciais simples (CPS) com desconforto e calor epigástricos ascendentes associados a distúrbios comportamentais como o medo. Ocorrem igualmente crises parciais complexas (CPC) nas quais existe perda da consciência associada a automatismos orofaciais e gestuais, podendo seguir generalização secundária. ${ }^{7}$ Apesar da maioria dos pacientes com diagnóstico de EMT responder de forma adequada ao tratamento clínico, $40 \%$ tornam-se refratários às drogas antiepilépticas. ${ }^{12} \mathrm{Nes}-$ tes casos, a cirurgia da epilepsia - amigdalo-hipocampectomia seletiva (AHS) - com a ressecção das estruturas mesiais do lobo temporal, uncus, amigdala e hipocampo é uma opção terapêutica. ${ }^{13,14}$ Entretanto, há morbimortalidade relacionada e, mesmo nos melhores centros, há um grupo de $20 \%-30 \%$ dos pacientes que continuam com crises epilépticas e necessitam de tratamento medicamentoso associado. ${ }^{15}$

\section{Por que pesquisar novas terapêuticas?}

Pesquisas realizadas nas últimas décadas trouxeram muitos avanços no desenvolvimento de fármacos antiepilépticos (FAEs). No entanto, um número significativo de pacientes não obtém resposta com a terapêutica medica- mentosa, e, além disso, tais medicações não previnem o desenvolvimento e progressão da doença.

Sabe-se que o deterioro mnemônico e das habilidades cognitivas ocorre nas epilepsias crônicas, particularmente em pacientes com epilepsia do lobo temporal, e é principalmente relacionado à idade e à duração da patologia. ${ }^{16,17}$ Também é importante salientar o alto risco de morte súbita nos pacientes com epilepsia refratária ao uso de fármacos antiepilépticos. ${ }^{18}$ Face a essas considerações, torna-se imprescindível a tentativa de cura ou de, pelo menos, melhora na qualidade de vida desses pacientes.

A ressecção cirúrgica focal de áreas cerebrais epileptogênicas é considerada a única terapêutica curativa disponível para pacientes com epilepsia. No entanto, é restrita a pacientes com epilepsia refratária ao tratamento medicamentoso, e muitos deles ainda necessitam manter o uso dessas medicações após a cirurgia. Há também muitas formas de epilepsia refratária que não são passíveis de tratamento cirúrgico. Ademais, a cirurgia de epilepsia implica custo financeiro elevado e, em algumas situações, riscos que devem ser considerados. O risco de ocorrerem complicações neurológicas pós-cirúrgicas varia entre $0 \%-25 \%$ e a mortalidade de 0\%-3\%. ${ }^{19,20}$ Dessa forma, a busca de estratégias terapêuticas menos invasivas e que tornem possível o tratamento da epilepsia a um maior número de pacientes é plenamente justificada.

\section{Epilepsia e neurogênese}

Os modelos experimentais de ELT utilizam o processo de kindling das estruturas límbicas (como amigdala e hipocampo) ou indução de status epiléptico induzido por lítiopilocarpina (ou outras substâncias como ácido kaínico); baseado nesses experimentos, formulou-se o conceito de que um dano neuronal inicial desencadeia uma cascata de eventos neurobiológicos que levam à ocorrência de crises espontâneas. ${ }^{21}$ Ao longo dos anos, esses experimentos também auxiliaram na quebra do conceito de que células neuronais adultas não poderiam se regenerar.

Até bem pouco tempo, a ciência desconhecia a capacidade regenerativa do cérebro. Sabe-se hoje que, a despeito do que se acreditou por décadas, novos neurônios podem, sim, ser integrados a determinadas regiões do encéfalo adulto a partir de células progenitoras neurais ou células-tronco adultas neurais, em um processo chamado neurogênese. ${ }^{22}$ Na maioria dos mamíferos, a neurogênese ocorre ao longo de toda a vida na zona subventricular do ventrículo lateral e na zona subgranular do giro denteado no hipocampo. ${ }^{23}$

A neurogênese induzida por crises epiléticas e também por outros insultos como isquemia cerebral já foi amplamente demonstrada. ${ }^{24} \mathrm{O}$ conceito de neurogênese no cérebro adulto, hoje já amplamente conhecida, principalmente a que ocorre na zona subventricular e na zona subgranular do giro denteado, motivou o desenvolvimento de técnicas que apro- 
veitassem esse mecanismo na tentativa de obtenção de efeitos antiepileptogênicos e reparadores. A maior parte dos estudos em vigência hoje e que buscam tal finalidade trabalha o uso de transplante de células progenitoras neurais ou de células fetais em modelos experimentais. ${ }^{25,26}$ No entanto, a terapêutica com células-tronco de medula óssea parece bastante interessante e promissora.

\section{Células-tronco}

As células-tronco (CT) representam uma unidade natural do desenvolvimento embrionário e da reparação tecidual e constituem um subconjunto de células imaturas, que têm como característica serem indiferenciadas e não-especializadas. Assim, estas células apresentam a capacidade tanto de se autorregenerar, ou seja, dividir-se e criar outras células-tronco, quanto de se diferenciar através de uma determinada via molecular e originar diferentes linhagens celulares. ${ }^{27}$

As células-tronco podem ser classificadas segundo a sua potencialidade de diferenciação, e algumas células são mais pluripotentes que as outras. São chamadas de totipotentes as células capazes de gerar todos os tipos celulares embrionários e extraembrionários, como o zigoto; podem originar todas as células que formam o embrião (propriamente dito) e são provenientes da camada interna do pré-embrião (blastocisto, $5^{\circ}$ dia de vida). As CT totipotentes têm a capacidade de originar células derivadas das três camadas germinativas: mesoderma, endoderma e ectoderma. As células-tronco adultas (pós-natal) são multipotentes capazes de gerar tipos celulares que compõem tecidos e órgãos específicos de seu local de origem, mas também pluripotentes, ou seja, com capacidade de gerar células de outros órgãos e tecidos. São pluripotentes, mas com a habilidade de diferenciação mais restrita. ${ }^{27-29}$

As células-tronco adultas, melhor denominadas somáticas por encontrarem-se na intimidade dos tecidos do corpo (soma), são responsáveis pelo reabastecimento tecidual ao longo da vida e estão presentes na maioria dos tecidos, tais como o sangue, a pele, o fígado, o coração e o cérebro. ${ }^{28}$ Acreditava-se que estas células teriam opções mais restritas de diferenciação, podendo selecionar um programa de diferenciação dentre apenas poucas vias possíveis. Entretanto, têm surgido evidências de que estas células poderiam transdiferenciar-se em células com origem germinativa distinta. Exemplos disto são os estudos de Bjornson e colaboradores ${ }^{30}$ que demonstraram que células isoladas a partir do encéfalo de camundongos transgênicos podem se diferenciar em células hematopoéticas, bem como os achados de Mezey e col., ${ }^{31}$ os quais comprovaram que células da medula óssea diferenciam-se em células que expressam marcadores neuronais. Em outro estudo, quando implantadas no encéfalo de ratos, células da medula óssea humanas não se transdiferenciaram em neurônios, mas perderam algumas de suas características e migraram por vias bem estabelecidas de migração neuronal. ${ }^{32}$ Entretanto, os dados obtidos até o momento não excluem totalmente explicações alternativas para a possível plasticidade de células-tronco adultas.$^{33}$ Assim, o debate continua em aberto ${ }^{34}$ quanto às observações de que essas células se transdiferenciam em células de tecidos diferentes daquele a partir do qual foram obtidas.

Por sua vez, a medula óssea (MO) é uma fonte permanente de células-tronco adultas. ${ }^{35}$ Uma das populações de células da MO, as células-tronco hematopoéticas, é responsável pela formação de todos os tipos de células sanguíneas do corpo. A população de células estromais da MO pode gerar, entre outros, osso e cartilagem. ${ }^{35,36}$ As células-tronco mesenquimais encontram-se imersas no estroma medular. Recentemente, uma população que se diferencia em células endoteliais foi identificada com sendo originária da medula óssea ${ }^{37}$ Assim, a MO parece conter três tipos de populações de células-tronco: hematopoéticas, estromais (mesenquimais) e possivelmente progenitoras endoteliais.

Apesar de já ter sido demonstrado que células da medula óssea de camundongos podem derivar-se em microglia, ${ }^{38}$ e neurônios in vivo, ${ }^{31,39}$ ainda não se sabe qual(is) subpopulação(ões) da MO foi(ram) capaz(es) de expressar este desenvolvimento neuronal. Além disso, a transdiferenciação de células da $\mathrm{MO}$ em neurônios no sistema nervoso central foi também demonstrada em seres humanos. ${ }^{40}$ Parece que a incorporação destas células no tecido nervoso é intensificada frente a um dano tecidual. Ainda, mesmo que estas células não regenerem o tecido lesado por se transdiferenciarem em determinado tipo celular, é provável que a recuperação de funções cerebrais ou estabilização da doença neurológica ocorra por outros mecanismos biológicos tais como a fusão celular, a liberação de fatores tróficos, citocinas ou ativação de células endógenas. ${ }^{41}$

As vantagens em se estudarem células-tronco adultas em contraste com as embrionárias incluem a maior facilidade de obtenção das primeiras, sendo que as célulastronco da MO podem ainda ser obtidas em maior quantidade (ideal para aplicação clínica) do que as demais célulastronco adultas. Ainda mais, elas podem ser obtidas a partir de uma pequena amostra de MO de um dado paciente, expandidas em cultura, e readministradas a este mesmo paciente. Assim, seria possível evitar problemas associados com a rejeição imunológica dos tecidos ou células transplantados. Finalmente, existem questões ético-religiosas que envolvem o uso de células-tronco embrionárias, que se anulam no caso de uso de células-tronco da medula óssea.

\section{Células-tronco no tratamento de doenças do sistema nervoso}

Nas doenças neurológicas, os danos são frequentemente irreversíveis, uma vez que mesmo que o sistema nervoso central adulto abrigue inúmeras células com potencial de regeneração, ele não consegue recrutá-las de maneira 
efetiva. Dessa maneira, estratégias que busquem promover acréscimo de número e função de células regenerativas endógenas, ou ainda introduzir células com potencial regenerativo no SNC através de transplante, podem representar novas alternativas terapêuticas neste caso.

Tendo em vista o contínuo progresso do conhecimento a respeito da capacidade regenerativa do encéfalo em conjunto com aquele sobre o potencial terapêutico das células-tronco, a reposição celular surge como uma alternativa promissora no tratamento das doenças neurológicas. As abordagens que vêm sendo estudadas em pesquisa pré-clínica são inúmeras e compreendem basicamente estratégias que têm como meta: a) a reposição seletiva de neurônios ou de células da glia que tenham sido perdidas no curso de uma determinada doença ou em decorrência de uma lesão; b) a indução de neurogênese endógena, ou ainda a regulação/ aumento da função das células remanescentes através da administração de células-tronco; as últimas seriam responsáveis por uma liberação de fatores tróficos capazes de promover essas modificações ou ainda prover neuroproteção ao tecido.

Dessa forma, têm surgido muitos estudos que avaliam a segurança e eficácia da administração de uma série de células das mais diversas origens: pluripotentes (i.e. embrionárias) ou de linhagem mais restrita como células-tronco ou progenitoras neurais (fetais ou adultas), ou células de linhagens não-neuronais (mesenquimais derivadas principalmente de cordão umbilical ou medula óssea). ${ }^{42}$ Além disso, células com potencial proliferativo limitado podem ser transformadas através de oncogenes, mas a aplicação clínica fica dificultada uma vez que essa técnica impõe questões adicionais de segurança. ${ }^{43}$

Exemplo do amplo interesse que essa estratégia terapêutica tem despertado são as recentes demonstrações que o transplante de células-tronco melhora a função cerebral fisiológica em modelos de isquemia cerebral, doença de Huntington e traumatismo raquimedular. ${ }^{44-47}$ Kim e colaboradores observaram melhora dos sintomas parkinsonianos em ratos que receberam células-tronco embrionárias neurais, com a geração de neurônios dopaminérgicos que detinham propriedades eletrofisiológicas e bioquímicas semelhantes às células mesencefálicas não transplantadas.$^{48}$ Mais, estudos recentes têm demonstrado a capacidade de diferenciação de células-tronco da medula óssea (CTMO) em progenitores celulares com características de células de Schwann, capazes de apoiar a regeneração em nervos ciáticos de ratos lesados após três semanas do transplante. ${ }^{49}$ Mimura e colaboradores demonstraram, em ratos adultos com nervos ciáticos seccionados, um aumento significativo na velocidade de condução e no índice de escala funcional para nervo ciático no grupo transplantado com células-tronco comparado ao grupo controle não transplantado após seis meses. ${ }^{50}$ Outros dados indicam que CTMO migram da corrente sanguínea para a área isquêmica e uma porcentagem pequena delas expressa marcadores neurais..$^{32,51,52}$ Da mesma maneira, o potencial terapêutico das CTMO também tem sido estudado em modelos de esclerose lateral amiotrófica, ${ }^{53,54}$ lesão da medula espinhal, ${ }^{55,56}$ doença de Parkinson, ${ }^{57,58}$ doença de Alzheimer, ${ }^{59}$ e doença de Huntington. ${ }^{60}$ Para mais, verificar Paula S et al. ${ }^{61}$

\section{Evidências experimentais do potencial terapêutico das células-tronco em modelos animais de epilepsia}

Estratégias terapêuticas envolvendo implantes de tecidos fetais foram as primeiras a ser estudadas em modelos experimentais de epilepsia. Entre elas está o uso de células fetais obtidas das regiões de CA1 e CA $3,{ }^{62}$ células liberadoras de adenosina, ${ }^{63}$ células produtoras de GABA. ${ }^{64}$ Logo, embora os efeitos do implante de tecido fetal hipocampal tenham sido amplamente pesquisados em modelos animais de epilepsia, ainda há muito poucos estudos a respeito da eficácia do transplante de células-tronco na ELT. ${ }^{25}$

Foi somente em 2004 que Chu e colaboradores ${ }^{65}$ exami- $^{-}$ naram os efeitos de células-tronco neurais obtidas da zona ventricular de embriões humanos nas crises espontâneas recorrentes de ratos com epilepsia. Esses animais foram tratados com pilocarpina, um agonista colinérgico cuja administração é capaz de reproduzir as alterações fisiopatológicas e comportamentais da epilepsia do lobo temporal. O transplante de células foi realizado 24 horas após a aplicação de pilocarpina, por via intravenosa. Entre 28 a 35 dias após o SE, apenas $13 \%$ dos animais que receberam as células apresentavam crises comportamentais. Além disso, as células doadoras, expressando $\beta$-galactosidase, coexpressavam marcadores de interneurônios como GABA e parvalbumina, sugerindo que as células derivadas do transplante se diferenciam em células sintetizantes de GABA. Em seu estudo, Chu obteve uma redução drástica na frequência de crises $(0,05+0,02 /$ dia nos animais transplantados $v s 1,37+0,22$ nos não transplantados).

Em seguida, Rüschenschmidt et al. transplantaram precursores neurais de camundongos nos hipocampos de ratos tratados com pilocarpina e controles. Verificaram, então, que estas células apresentavam propriedades intrínsecas e sinápticas características de neurônios. Os pesquisadores não observaram diferenças nas propriedades funcionais entre células transplantadas em ratos epilépticos ou controles ${ }^{66}$

Em nosso laboratório, temos estudado o potencial terapêutico de células-tronco da medula óssea no controle de crises espontâneas recorrentes associadas ao modelo da pilocarpina. Ao administrar células da camada mononuclear da medula óssea, por via intravenosa, imediatamente após a aplicação de pilocarpina, verificamos que as células transplantadas migraram até o cérebro epiléptico e sobreviveram 1, 3, 5, 10 e 120 dias após o transplante. Algumas das células expressavam marcadores para microglia e neurônios jovens. 
Além disso, as células parecem ter contribuído para uma menor perda neuronal nos animais tratados e na preservação do volume hipocampal. Quando avaliada a funcionalidade do tecido, houve maior facilidade de se obter LTP (Potenciação de longa duração) no grupo transplantado versus o grupo epiléptico que não recebeu células-tronco. Finalmente, apenas $20 \%$ dos animais do grupo transplantado apresentaram crises espontâneas recorrentes após 120 dias. Quando as células foram administradas, também perifericamente, 22 dias após a injeção de pilocarpina, verificou-se que os animais tiveram uma diminuição na frequência das crises de aproximadamente $50 \%$. Células transplantadas foram encontradas dispersas por todo o cérebro dos animais epilépticos 45 dias após o transplante, em maior quantidade nas áreas corticais e no giro denteado do hipocampo, algumas expressando marcadores neuronais. No estudo eletrofisiológico, a LTP induzida por estimulação tetânica foi obtida em $100 \%$ das fatias de animais controles não epilépticos, em $100 \%$ das fatias de animais epilépticos tratados com CTMO e em nenhuma das fatias dos animais epilépticos tratados com solução salina. Os dados indicam que o transplante de células da medula óssea protege e/ou previne a progressão da epilepsia crônica. (Costa-Ferro, Z.S. "Transplante de células da medula óssea na epilepsia experimental induzida por lítio e pilocarpina em ratos" Tese de Doutorado apresentada ao programa de Pós-Graduação em Fisiologia da Universidade Federal do Rio Grande do Sul. Agosto de 2008)

É válido lembrar que na ELT é comum haver déficit cognitivo, seja em pacientes ou em modelos experimentais. ${ }^{67,68}$ Animais tratados com pilocarpina sabidamente apresentam déficit de memória espacial, associado com a grande morte de células hipocampais induzida pelo modelo. Entretanto, as células injetadas reverteram esse déficit, promovendo não só redução da frequência de crises espontâneas recorrentes, mas também melhora cognitiva na tarefa do labirinto aquático de Morris Venturin, G.T. "Efeito do transplante de células mononucleares da medula óssea na frequência de crises e no desempenho cognitivo de ratos com epilepsia induzida por lítio-pilocarpina" Dissertação de Mestrado apresentada ao programa de Pós-Graduação em Neurociências da Universidade Federal do Rio Grande do Sul. Junho de 2008.

$\mathrm{Na}$ maioria dos mamíferos, a neurogênese ocorre ao longo de toda a vida na zona subventricular do ventrículo lateral e na zona subgranular do giro denteado no hipocampo. Os fatores que regulam essa proliferação in vivo ainda não foram totalmente caracterizados, mas membros das famílias de fatores de crescimento FGF (fator de crescimento de fibroblasto) e EGF (fator de crescimento epidérmico) são usados para propagar progenitores neurais in vitro e podem ter funções semelhantes in vivo. ${ }^{23}$ As células-tronco poderiam promover a recuperação funcional por outros meios que não a reposição celular direta, como, por exemplo, pela secreção de fatores tróficos. Esses fatores tróficos poderiam, por sua vez, promover a sobrevivência, migração e diferenciação de células progenitoras neurais endógenas. ${ }^{69}$ Assim, as CT transplantadas poderiam exercer um efeito trófico direto no tecido ou levar a uma elevação da atividade trófica endógena.

A ideia de que o mecanismo de ação das CT pode estar ligado a fatores tróficos é reforçada por trabalhos que apontam que o tratamento de células doadoras com uma mistura de FGF-2 (fator de crescimento de fibroblasto) e BDNF (fator de crescimento neurotrófico cerebral-derivado), anterior ao enxerto dessas células fetais no hipocampo, é eficiente na supressão da epileptogênese, ${ }^{70}$ e que o FGF-2, por exemplo, contribui com a sobrevivência e diferenciação de neurônios hipocampais em desenvolvimento em condições adversas. ${ }^{71}$ Ainda, Kanter-Schlifke e colaboradores demonstraram em estudo com terapia gênica que a expressão aumentada de GDNF no hipocampo de ratos suprime crises epilépticas em modelo de abrasamento e status epilepticus (SE). ${ }^{72}$

Finalmente, se por um lado o SE induz um aumento inicial na neurogênese no giro denteado ${ }^{73}$ a epilepsia do lobo temporal crônica está associada com neurogênese consideravelmente diminuída. ${ }^{74}$ Hattiangady e colegas demonstraram também que o declínio na neurogênese é consideravelmente maior em ratos que apresentam um maior número de crises espontâneas recorrentes (CERs), sugerindo que a maior frequência de CERs durante a epilepsia crônica é prejudicial à neurogênese no giro denteado. ${ }^{74}$ Soma-se a isso o fato de que durante a epilepsia crônica há queda na concentração de diversos fatores tróficos que atuam na proliferação de células-tronco neurais e que a neurogênese diminuída pode contribuir para a persistência de crises e déficits de memória e aprendizagem. ${ }^{74,75}$ Logo, estratégias que aumentem a produção de neurônios no hipocampo epiléptico, como o transplante de CT, seja exercendo efeito trófico direto ou elevando a atividade trófica endógena, podem ser úteis para o tratamento da epilepsia do lobo temporal.

\section{Estudos clínicos avaliando o potencial terapêutico das células-tronco de medula óssea na epilepsia}

Sem dúvida, os excelentes resultados obtidos com os modelos experimentais conduzidos pelo grupo do nosso laboratório incentivaram o desenvolvimento de pesquisas translacionais também conduzidas pelo nosso grupo.

O primeiro projeto a adotar a terapêutica com células-tronco em doenças neurológicas avaliou a segurança do procedimento em vinte pacientes com acidente vascular cerebral (AVC) isquêmico (Araujo, M.D. "Segurança do transplante autólogo de células mononucleares de medula óssea no acidente vascular cerebral isquêmico agudo extenso da artéria cerebral média." Dissertação apresentada ao curso de Pós-Graduação em Medicina e Ciências da Saúde da Pontifícia Universidade Católica do Rio Grande do Sul como parte dos requisitos para a obtenção do título de Mestre em Medicina - Neurociências. Porto Alegre, março de 2008). ${ }^{76}$ Em dezem- 
bro de 2007 o Conep aprovou a execução do primeiro estudo em humanos utilizando terapia com células-tronco para o tratamento da epilepsia. Iniciado em 2008, esse estudo tem como objetivo avaliar a segurança e eficácia do procedimento em pacientes rigorosamente selecionados. São alocados para o estudo pacientes que tenham história clínica de ELT bem documentada através de eletroencefalograma e ressonância magnética, os quais devem evidenciar alterações claras compatíveis com a síndrome clínica. Após a seleção, os pacientes iniciam um processo de reavaliação intra-hospitalar, no qual são submetidos novamente à ressonância magnética (que deve confirmar o achado de esclerose mesial temporal). Segue, durante 48 a 72 horas, investigação por meio de videoeletroencefalograma (video EEG), cujo objetivo é registrar as crises epiléticas originadas no lobo temporal. São também submetidos à extensa avaliação neuropsicológica a fim de verificar a existência de possíveis déficits de memória e disfunção executiva. Após a verificação da congruência dos dados, os pacientes são então submetidos ao implante das células-tronco de medula óssea por meio de arteriografia (via abordagem da artéria cerebral posterior).

A primeira paciente participante do estudo foi submetida ao transplante de células-tronco em julho de 2008. Atualmente, com seis meses de seguimento, vem apresentando uma resposta terapêutica animadora no que diz respeito ao controle de crises e ao desempenho cognitivo. E mais do que isso, sem registro de efeitos adversos. Sem dúvida, há uma grande expectativa de resposta clínica efetiva e segura nos demais pacientes já em estudo.

\footnotetext{
Abstract

Epilepsy is a prevalent pathology. A significative number of patients do not achieve an adequate response to pharmacological therapy. This observation has motivated the search for new strategies. The now well known concept of neurogenesis in the adult brain, in particular in the subventricular and dentate gyrus subgranular zones, has encouraged the development of strategies that might control this mechanism in order to obtain either antiepileptogenic or repair effects. Most studies focus on the transplantation of neural progenitor or fetal cells in experimental models, although bone marrow stem cell therapy is promising. In neurological diseases in which damage is frequently irreversible, regenerative strategies could represent a new path towards better treatment options. In our laboratory, we have been studying the therapeutic potential of bone marrow stem cells in controlling recurrent spontaneous seizures associated to the pilocarpine model of epilepsy with excellent results. We are also running the first study using bone marrow stem cell transplantation in the treatment of epilepsy in humans. Rev. Bras. Hematol. Hemoter. 2009;31(Supl. 1):112-119.
}

Key words: Stem cells; bone marrow; epilepsy.

\section{Referências Bibliográficas}

1. Loddenkemper T, Lüders HO. History of epilepsy and seizure classification. In: Textbook of epilepsy surgey, por HO Lüders. Informa Healthcare. 2008. 160-173.

2. Gastaut, H. Epileptic Seizures. Dev Med Child Neurol. 1973. 688-689.

3. Rogawski MA, Porter RJ. Antiepileptic drugs: pharmacological mechanisms and clinical efficacy with consideration of promising developmental stage compounds. Pharmacol Rev. 1990; 42(3): 223-86.

4. McNamara JO. Cellular and molecular basis of epilepsy. J Neurosci. 1994;14(6):3413-25

5. Sander JW e YM Hart. A epidemiologia da epilepsia. In: Epilepsia: Um Guia Prático. Merit - Publishing International. 1999.

6. Engel J Jr; International League Against Epilepsy (ILAE). A proposed diagnostic scheme for people with epileptic seizures and with epilepsy: report of the ILAE Task Force on Classification and Terminology. Epilepsia. 2001;42(6):796-803.

7. Cendes FP, Kahane M, Brodie F, Andermann. The mesio-temporal lobe epilepsy syndrome. In: Epileptic Syndrome in infancy, childhood and adolescence, por Roger J, Bureau M, Dravet C, Genton P, Tassinari CA e Wolf P. Montrouge: John Libbey Eurotext. 2005;555-75.

8. Lüders HO. Mesial temporal sclerosis. In: Lüders HO. Textbook of Epilepsy Surgery. Informa Healthcare. 2008;249-51.

9. Valerio RMF, Yacubian EMT, Rosemberg SR. Anatomia patológica em 33 pacientes com epilepsia do lobo temporal. Brazilian J Epilepsy Clin Neurophysol. 1995;1(2):67-74.

10. Majores M, Schoch S, Lie A, Becker AJ. Molecular neuropathology of temporal lobe epilepsy: complementary approaches in animal models and human disease tissue. Epilepsia. 2007;48 Suppl 2:4-12.

11. Blümcke I, Beck H, Scheffler B, Hof PR, Morrison JH, Wolf HK, et al. Altered distribution of the alpha-amino-3-hydroxy-5-methyl4-isoxazole propionate receptor subunit GluR2(4) and the N-methylD-aspartate receptor subunit NMDAR1 in the hippocampus of patients with temporal lobe epilepsy. Acta Neuropathol. 1996; 92(6):576-87.

12. Palmini ALF, DaCosta JC, Calcagnotto ME, Martinez JVL. Avaliação pré-cirúrgica de pacientes com epilepsia parcial refratária. In: DaCosta JC, Palmini ALF e Yacubian EMT. Fundamentos Neurobiológicos das Epilepsias: Aspectos Clínicos e Cirúrgicos. São Paulo: Lemos Editorial. 1998. 857-78.

13. Palmini ALF e DaCosta JC. Seleção de candidatos à cirurgia da epilepsia: A inseparável parceria entre conhecimento e bom senso. In: DaCosta JC, Palmini ALF e Yacubian EMT. Fundamentos Neuroiológicos das Epilepsias: Aspectos Clínicos e Cirúrgicos. São Paulo: Lemos Editorial. 1998. 833-56.

14. Palmini ALF, DaCosta JC, Paglioli-Neto E. How to select the best surgical procedure for patients with temporal lobe epilepsy. In: Lüders HO e Comair YG. Epilepsy Surgery. Lippincott Wilians \& Wilkins. 675-684.

15. Paglioli E, Palmini A, Paglioli E, da Costa JC, Portuguez M, Martinez JV, et al. Survival analysis of the surgical outcome of temporal lobe epilepsy due to hippocampal sclerosis. Epilepsia. 2004;45(11):1383-91.

16. Helmstaedter C, Kurthen M. Memory and epilepsy: characteristics, course, and influence of drugs and surgery. Curr Opin Neurol. 2001; 14(2):211-6.

17. Helmstaedter C, Kurthen M, Lux S, Reuber M, Elger CE. Chronic epilepsy and cognition: a longitudinal study in temporal lobe epilepsy. Ann Neurol. 2003;54(4):425-32. 
18. Walczak TS, Leppik IE, D'Amelio M, Rarick J, So E, Ahman P, et al. Incidence and risk factors in sudden unexpected death in epilepsy: a prospective cohort study. Neurology, 2001; 56: 519-25.

19. De Paol, L, Sakamoto A, Cendes F, Arruda F, Castro F. Critérios mínimos para a realização do tratamento cirúrgico de epilepsia. Indicação para admissão de pacientes em protocolos de investigação para o tratamento cirúrgico das epilepsias. Brazilian J Epilepsy Clin Neurophysol. 2001;76-9.

20. Schwager HW, Kanoti GA. Ethical considerations in surgery of epilepsy. In: Ethical considerations in surgery of epilepsy, por Schwager HW e Kanoti GA. New York: Raven Press, 1991.

21. Morimoto K, Fahnestock M, Racine RJ. Kindling and status epilepticus models of epilepsy: rewiring the brain. Prog Neurobiol. 2004;73(1):1-60.

22. Gross CG. Neurogenesis in the adult brain: death of a dogma. Nat Rev Neurosci. 2000;1(1):67-73.

23. Ming GL, Song H. Adult neurogenesis in the mammalian central nervous system. Annu Rev Neurosci. 2005;28:223-50.

24. Parent JM. Injury-induced neurogenesis in the adult mammalian brain. Neuroscientist. 2003;9(4):261-72.

25. Shetty AK, Hattiangady B. Concise review: prospects of stem cell therapy for temporal lobe epilepsy. Stem Cells. 2007;25(10):2396407.

26. Löscher W, Gernert M, Heinemann U. Cell and gene therapies in epilepsy--promising avenues or blind alleys? Trends Neurosci. 2008;31(2):62-73.

27. Morrison SJ, Shah NM, Anderson DJ. Regulatory mechanisms in stem cell biology. Cell. 1997;88(3):287-98.

28. Kaji EH, Leiden JM. Gene and stem cell therapies. JAMA. $2001 ; 285(5): 545-50$.

29. Fuchs E, Segre JA. Stem cells: a new lease on life. Cell. 2000; 100(1):143-55.

30. Bjornson CR, Rietze RL, Reynolds BA, Magli MC, Vescovi AL. Turning brain into blood: a hematopoietic fate adopted by adult neural stem cells in vivo. Science. 1999;283(5401):534-7.

31. Mezey E, Chandross KJ, Harta G, Maki RA, McKercher SR. Turning blood into brain: cells bearing neuronal antigens generated in vivo from bone marrow. Science. 2000;290(5497):1779-82.

32. Azizi SA, Stokes D, Augelli BJ, DiGirolamo C, Prockop DJ. Engraftment and migration of human bone marrow stromal cells implanted in the brains of albino rats--similarities to astrocyte grafts. Proc Natl Acad Sci U S A. 1998;95(7):3908-13.

33. Frisén J. Stem cell plasticity? Neuron. 2002;35(3):415-8.

34. Phinney DG, Prockop DJ. Concise review: mesenchymal stem/ multipotent stromal cells: the state of transdifferentiation and modes of tissue repair - current views. Stem Cells. 2007; 25 (11): 2896-902.

35. Kørbling M, Estrov Z. Adult stem cells for tissue repair - a new therapeutic concept? N Engl J Med. 2003;349(6):570-82.

36. Petersen BE, Bowen WC, Patrene KD, Mars WM, Sullivan AK, Murase $\mathrm{N}$, et al. Bone marrow as a potential source of hepatic oval cells. Science. 1999;284(5417):1168-70.

37. Shi Q, Rafii S, Wu MH, Wijelath ES, Yu C, Ishida A, et al. Evidence for circulating bone marrow-derived endothelial cells. Blood. 1998;92(2):362-7.

38. Eglitis MA, Mezey E. Hematopoietic cells differentiate into both microglia and macroglia in the brains of adult mice. Proc Natl Acad Sci USA. 1997;94(8):4080-5.

39. Brazelton TR, Rossi FM, Keshet GI, Blau HM. From marrow to brain: expression of neuronal phenotypes in adult mice. Science. 2000;290(5497):1775-9.
40. Cogle CR, Yachnis AT, Laywell ED, Zander DS, Wingard JR, Steindler DA, et al. Bone marrow transdifferentiation in brain after transplantation: a retrospective study. Lancet. 2004;363 (9419): 1432-7.

41. Terada N, Hamazaki T, Oka M, Hoki M, Mastalerz DM, Nakano $\mathrm{Y}$, et al. Bone marrow cells adopt the phenotype of other cells by spontaneous cell fusion. Nature. 2002;416(6880):542-5.

42. Conti L, Cataudella T, Cattaneo E. Neural stem cells: a pharmacological tool for brain diseases? Pharmacol Res. 2003; 47(4):289-97.

43. Rosser AE, Zietlow R, Dunnett SB. Stem cell transplantation for neurodegenerative diseases. Curr Opin Neurol. 2007;20 (6): 688-92.

44. Haas S, Weidner N, Winkler J. Adult stem cell therapy in stroke. Curr Opin Neurol. 2005;18(1):59-64.

45. Bang OY, Lee JS, Lee PH, Lee G. Autologous mesenchymal stem cell transplantation in stroke patients. Ann Neurol. 2005;57(6): 874-82.

46. Dunnett SB, Rosser AE. Cell therapy in Huntington's disease. NeuroRx. 2004;1(4):394-405.

47. Koda M, Okada S, Nakayama T, Koshizuka S, Kamada T, Nishio Y, et al. Hematopoietic stem cell and marrow stromal cell for spinal cord injury in mice. Neuroreport. 2005;16(16):1763-7.

48. Kim JH, Auerbach JM, Rodríguez-Gómez JA, Velasco I, Gavin D, Lumelsky $\mathrm{N}$, et al. Dopamine neurons derived from embryonic stem cells function in an animal model of Parkinson's disease. Nature. 2002;418(6893):50-6.

49. Dezawa M, Takahashi I, Esaki M, Takano M, Sawada H. Sciatic nerve regeneration in rats induced by transplantation of in vitro differentiated bone-marrow stromal cells. Eur J Neurosci. 2001; 14(11):1771-6.

50. Mimura T, Dezawa M, Kanno H, Sawada H, Yamamoto I. Peripheral nerve regeneration by transplantation of bone marrow stromal cell-derived Schwann cells in adult rats. J Neurosurg. 2004; 101(5): 806-12.

51. Eglitis MA, Dawson D, Park KW, Mouradian MM. Targeting of marrow-derived astrocytes to the ischemic brain. Neuroreport. 1999;10(6):1289-92.

52. Li Y, Chen J, Chopp M. Adult bone marrow transplantation after stroke in adult rats. Cell Transplant. 2001;10(1):31-40.

53. Vercelli A, Mereuta OM, Garbossa D, Muraca G, Mareschi K, Rustichelli $\mathrm{D}$, et al. Human mesenchymal stem cell transplantation extends survival, improves motor performance and decreases neuroinflammation in mouse model of amyotrophic lateral sclerosis. Neurobiol Dis. 2008;31(3):395-405.

54. Corti S, Locatelli F, Donadoni C, Guglieri M, Papadimitriou D, Strazzer S, et al. Wild-type bone marrow cells ameliorate the phenotype of SOD1-G93A ALS mice and contribute to CNS, heart and skeletal muscle tissues. Brain. 2004;127(Pt 11):2518-32.

55. Ankeny DP, McTigue DM, Jakeman LB. Bone marrow transplants provide tissue protection and directional guidance for axons after contusive spinal cord injury in rats. Exp Neurol. 2004;190(1):17-31.

56. Callera F, de Melo CM. Magnetic resonance tracking of magnetically labeled autologous bone marrow CD34+ cells transplanted into the spinal cord via lumbar puncture technique in patients with chronic spinal cord injury: $\mathrm{CD} 34+$ cells' migration into the injured site. Stem Cells Dev. 2007;16(3):461-6.

57. Bouchez G, Sensebé L, Vourc'h P, Garreau L, Bodard S, Rico A, et al. Partial recovery of dopaminergic pathway after graft of adult mesenchymal stem cells in a rat model of Parkinson's disease. Neurochem Int. 2008;52(7):1332-42. 
58. Levy YS, Bahat-Stroomza M, Barzilay R, Burshtein A, Bulvik S, Barhum Y, et al. Regenerative effect of neural-induced human mesenchymal stromal cells in rat models of Parkinson's disease. Cytotherapy. 2008;10(4):340-52.

59. Li LY, Li JT, Wu QY, Li J, Feng ZT, Liu S, Wang TH. Transplantation of NGF-gene-modified bone marrow stromal cells into a rat model of Alzheimer' disease. J Mol Neurosci. 2008;34(2):157-63.

60. Lescaudron L, Unni D, Dunbar GL. Autologous adult bone marrow stem cell transplantation in an animal model of huntington's disease: behavioral and morphological outcomes. Int J Neurosci. 2003; 113(7):945-56.

61. Paula $\mathrm{S}$, et al. O potencial terapêutico das células-tronco. Scientia Medica. 2005;15(4):263-9.

62. Zaman V, Turner DA, Shetty AK. Survival of grafted fetal neural cells in kainic acid lesioned CA3 region of adult hippocampus depends upon cell specificity. Exp Neurol. 2000; 161(2):535-61.

63. Huber A, Padrun V, Déglon N, Aebischer P, Möhler H, Boison D. Grafts of adenosine-releasing cells suppress seizures in kindling epilepsy. Proc Natl Acad Sci USA. 2001;98(13):7611-6.

64. Gernert M, Thompson KW, Löscher W, Tobin AJ. Genetically engineered GABA-producing cells demonstrate anticonvulsant effects and long-term transgene expression when transplanted into the central piriform cortex of rats. Exp Neurol. 2002;176 (1):183-92 .

65. Chu K, Kim M, Jung KH, Jeon D, Lee ST, Kim J, et al. Human neural stem cell transplantation reduces spontaneous recurrent seizures following pilocarpine-induced status epilepticus in adult rats. Brain Res. 2004;1023(2):213-21.

66. Rüschenschmidt C, Koch PG, Brüstle O, Beck H. Functional properties of ES cell-derived neurons engrafted into the hippocampus of adult normal and chronically epileptic rats. Epilepsia. 2005;46 Suppl 5:174-83.

67. Holmes GL. Epilepsy in the developing brain: lessons from the laboratory and clinic. Epilepsia. 1997;38(1):12-30.

68. Liu Z, Gatt A, Werner SJ, Mikati MA, Holmes GL. Long-term behavioral deficits following pilocarpine seizures in immature rats. Epilepsy Research. 1994;19:191-204.

69. Chopp M, Li Y. Treatment of neural injury with marrow stromal cells. Lancet Neurol. 2002;1(2):92-100.

70. Rao MS, Hattiangady B, Shetty AK. Fetal hippocampal CA3 cell grafts enriched with FGF-2 and BDNF exhibit robust long-term survival and integration and suppress aberrant mossy fiber sprouting in the injured middle-aged hippocampus. Neurobiol Dis. 2006; 21(2):276-90.

71. Eves EM, Skoczylas C, Yoshida K, Alnemri ES, Rosner MR. FGF induces a switch in death receptor pathways in neuronal cells. J Neurosci. 2001;21(14):4996-5006.

72. Kanter-Schlifke I, Georgievska B, Kirik D, Kokaia M. Seizure suppression by GDNF gene therapy in animal models of epilepsy. Mol Ther. 2007;15(6):1106-13.

73. Parent JM, Yu TW, Leibowitz RT, Geschwind DH, Sloviter RS, Lowenstein DH. Dentate granule cell neurogenesis is increased by seizures and contributes to aberrant network reorganization in the adult rat hippocampus. J Neurosci. 1997;17(10):3727-38.

74. Hattiangady B, Rao MS, Shetty AK. Chronic temporal lobe epilepsy is associated with severely declined dentate neurogenesis in the adult hippocampus. Neurobiol Dis. 2004;17(3):473-90.

75. Shetty AK, Zaman V, Shetty GA. Hippocampal neurotrophin levels in a kainate model of temporal lobe epilepsy: a lack of correlation between brain-derived neurotrophic factor content and progression of aberrant dentate mossy fiber sprouting. J Neurochem. 2003; 87(1):147-59.

76. Friedrich MAG, et al. Transplantation of autologous bone marrow mononuclear Cells (ABMMNC) in acute large middle cerebral artery (MCA) stroke. International Journal of Stroke. 2006.

Suporte Financeiro: Os estudos realizados em nosso laboratório receberam suporte financeiro da Capes, CNPq, PUCRS, Funpar, Pandurata e Faculdade Gama e Souza.

Avaliação: O tema apresentado consta da pauta elaborada pelo editor, Professor Milton Artur Ruiz e coeditores deste suplemento, Professores Sergio Paulo Bydlowski e Adriana Seber.

Conflito de interesse: não declarado

Recebido: 21/01/2009

Aceito: 16/04/2009 